Chronic Obstructive Pulmonary Diseases: Journal of the COPD Foundation

\author{
Original Research
}

\title{
Safety and Efficacy of Revefenacin and Formoterol in Sequence and Combination via a Standard Jet Nebulizer in Patients with Chronic Obstructive Pulmonary Disease: A Phase 3b, Randomized, 42-Day Study
}

Thomas M. Siler, $\mathrm{MD}^{1}$ Edmund J. Moran, $\mathrm{PhD}^{2}$ Chris N. Barnes, $\mathrm{PhD}^{2}$ Glenn D. Crater, $\mathrm{MD}^{2}$

\begin{abstract}
Although no nebulized, dual mechanism, long-acting bronchodilator is currently marketed, with the approval of once-daily long-acting muscarinic antagonist (LAMA) revefenacin, it is theoretically possible to deliver a LAMA and long-acting beta2-agonist via standard jet nebulizer. The primary and secondary objectives of our study were to characterize the safety profile of revefenacin administered sequentially before or in combination with formoterol, via standard jet nebulizer in patients with moderate to very severe chronic obstructive pulmonary disease (COPD). In this randomized, double-blind, 42-day trial (NCT03573817), patients received revefenacin $175 \mu \mathrm{g}(\mathrm{n}=63)$ or placebo ( $\mathrm{n}=59)$, followed by formoterol $20 \mu \mathrm{g}$ in the morning and formoterol alone in the evening for 21 days via standard jet nebulizer (sequential administration). For another 21 days, revefenacin/ placebo and formoterol, were administered as mixed solutions via single nebulization in the morning (combined administration), and formoterol alone in the evening. The adverse events' (AEs) incidence was higher in the placebo and formoterol arms (11\%-12\%) than in the revefenacin and formoterol arms (5\%-8\%). The most common AEs were worsening/exacerbation of COPD, cough, and dizziness. There were no serious AEs or deaths reported in any arm. The least squares mean in trough forced expiratory volume in 1 second (FEV $)_{1}$ versus baseline was higher in the revefenacin and formoterol arms (116-157 mL) than in the placebo and formoterol arms (35-53 mL). Revefenacin had a safety profile similar to formoterol alone when delivered sequentially or combined. Trough FEV 1 was similar when revefenacin was delivered sequentially or combined with formoterol, with revefenacin providing an additional 81-104 $\mathrm{mL}$ improvements over formoterol alone.
\end{abstract}

\footnotetext{
Abbreviations: long-acting muscarinic antagonist, LAMA; chronic obstructive pulmonary disease, COPD; adverse events, AEs; forced expiratory volume in 1 second, FEV $\mathbf{1}$; long-acting beta2-agonists, LABA; forced vital capacity, FVC; electrocardiogram, ECG; confidence interval, CI

Funding Support: This study was funded by Theravance Biopharma, Ireland Limited (Dublin, Ireland). Mylan Inc., (Canonsburg, Pennsylvania) and Theravance Biopharma US, Inc., (South San Francisco, California) funded medical writing support.

Date of Acceptance: February 4, 2020

Citation: Siler TM, Moran EJ, Barnes CN, Crater GD. Safety and efficacy of revefenacin and formoterol in sequence and combination via a standard jet nebulizer in patients with chronic obstructive pulmonary disease: a phase 3b, randomized, 42-day study. Chronic Obstr Pulm Dis. 2020;7(2):99-106. doi: https://doi.org/10.15326/jcopdf.7.2.2019.0154
}

1 Midwest Chest Consultants, PC, St Charles, Missouri

2 Theravance Biopharma US, Inc., South San Francisco, California

\section{Address correspondence to:}

Glenn D. Crater, MD

Phone: (650) 808-4078

Email: gcrater@theravance.com

\section{Keywords:}

combined administration; chronic obstructive pulmonary disease; COPD; dual administration; phase 3 randomized controlled trial; revefenacin; safety; sequential administration; standard jet nebulizer 


\section{Introduction}

Treatment with inhaled bronchodilators is the mainstay of symptom management in patients with chronic obstructive pulmonary disease (COPD). Longacting muscarinic antagonists (LAMAs), long-acting beta2-agonists (LABAs), or a combination of a LAMA/ LABA for more severe symptoms, is recommended as the first-line treatment for patients with COPD. ${ }^{1}$

Revefenacin inhalation solution is a once-daily LAMA delivered by a standard jet nebulizer that is approved by the U.S. Food and Drug Administration for the maintenance treatment of patients with COPD. ${ }^{2}$ Revefenacin was shown to be well-tolerated for 52 weeks and has a safety profile that supports its long-term use in patients with COPD. ${ }^{3}$ In addition, the efficacy of revefenacin has been demonstrated in 2 replicate, randomized, controlled, phase 3 trials in a broad population of patients with moderate to very severe COPD with or without concurrent LABAs. ${ }^{4}$ In these studies, revefenacin significantly improved lung function (trough forced expiratory volume in 1 second $\left[F E V_{1}\right]$ and overall treatment effect $F E V_{1}$ ) compared with placebo. ${ }^{4}$ Revefenacin was also shown to improve $\mathrm{FEV}_{1}$ and respiratory health outcomes over 52 weeks with results similar to tiotropium via HandiHaler. ${ }^{5}$

As outlined by the Global initiative for chronic Obstructive Lung Disease (GOLD) report, LAMA/ LABA combinations are among the favored treatment choices in highly symptomatic patients for preventing $\mathrm{COPD}$ exacerbations, increasing $\mathrm{FEV}_{1}$, and reducing symptoms. ${ }^{1}$ The GOLD report does not recommend one inhalation device over another for maintenance therapy in patients with COPD. However, nebulized therapy might be beneficial among patients who have physical and/or cognitive symptoms (e.g., the elderly). ${ }^{6}$

Although no nebulized, dual mechanism, long-acting bronchodilator product is currently marketed, with the approval of revefenacin, it is theoretically possible to deliver a LAMA and a LABA via a standard jet nebulizer. Here, we assess the safety and tolerability of revefenacin administered either sequentially before or combined with formoterol, via a standard jet nebulizer (PARI LC ${ }^{\circledast}$ Sprint; Starnberg, Germany) in patients with COPD. Exploratory efficacy assessments were also reported.

\section{Methods}

\section{Study Design and Conduct}

This was a 42-day, randomized, double-blind, 2-period, parallel-group, phase $3 \mathrm{~b}$ trial (NCT03573817). The trial was conducted according to the principles of the International Council for Harmonisation of Technical Requirements for Pharmaceuticals for Human Use Guideline for Good Clinical Practice, ${ }^{7}$ and the code of ethics of the World Medical Association's Declaration of Helsinki ${ }^{8}$; written informed consent was obtained from all patients. The protocol was reviewed and approved by an institutional review board (Advarra IRB, Columbia, Maryland).

\section{Patients and Treatments}

The goal was to enroll approximately 120 patients (aged $\geq 40$ years) with a diagnosis of moderate to very severe COPD. Patients were included if they had a smoking history $\geq 10$ pack years, a post-ipratropium FEV 1 / forced vital capacity $(F V C)$ ratio $<0.7$ at screening, and a post-ipratropium $\mathrm{FEV}_{1}$ value $<80 \%$ of predicted normal and $>700 \mathrm{~mL}$ at screening. Patients were excluded if they had a significant respiratory disorder or disease other than COPD, elevated cardiovascular risk (e.g., myocardial infarction or unstable angina within the previous 6 months, unstable or lifethreatening arrhythmia requiring intervention in the previous 3 months, or New York Heart Association Class IV heart failure) or exhibited a clinically significant abnormality in 12-lead electrocardiogram (ECG) at screening, or uncontrolled hypertension, hypercholesterolemia, or type 2 diabetes. Patients were also ineligible for participation if they were hospitalized for COPD or pneumonia within 8 weeks of screening or had used systemic corticosteroids or antibiotics within 8 weeks of screening. Patients underwent an ipratropium reversibility test after a screening visit and washout period for those who were taking medications that were prohibited during the trial (e.g., other LAMAs and LABAs).

Patients were randomized $1: 1$ to 1 of 2 treatment groups and received treatment twice daily for two 21day periods (Figure 1). Revefenacin was assigned in a double-blind manner and formoterol was administered open label. 


\section{Figure 1. Study Design}

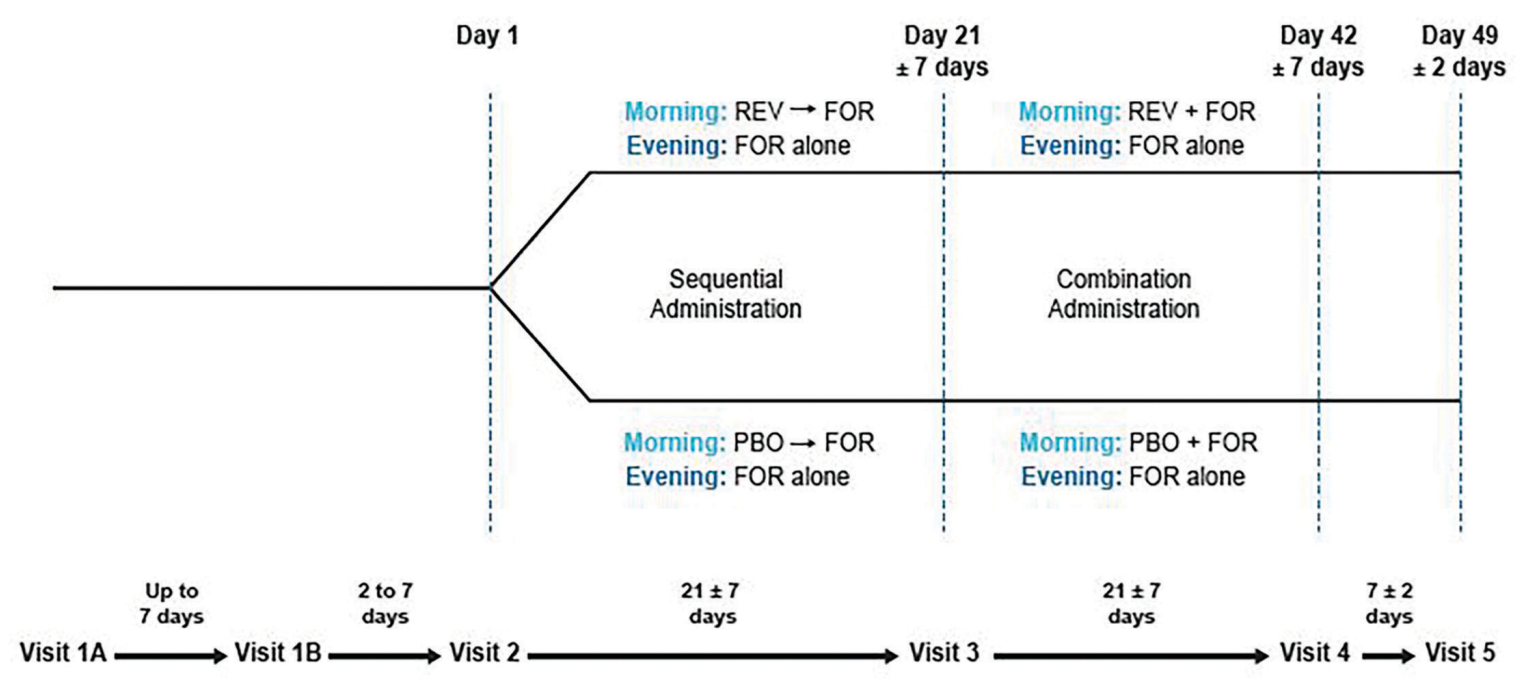

Screening

Randomization and Treatment

--Follow-Up --

$\mathrm{REV}=$ revefenacin; $F O R=$ formoterol; $\mathrm{PBO}=$ placebo

\section{Treatment Group 1}

- Days 1 to 21 (Period 1): morning administration of revefenacin $175 \mu \mathrm{g}$ via a standard jet nebulizer as a $3 \mathrm{~mL}$ solution, immediately followed by formoterol $20 \mu \mathrm{g}$ via a standard jet nebulizer as a $2 \mathrm{~mL}$ solution. Formoterol $20 \mu \mathrm{g}$ was administered again alone in the evening as a $2 \mathrm{~mL}$ solution.

- Days 22 to 42 (Period 2): morning administration of revefenacin $175 \mu \mathrm{g}$ mixed with formoterol $20 \mu \mathrm{g}$ via standard jet nebulizer as a $5 \mathrm{~mL}$ solution. Formoterol $20 \mu \mathrm{g}$ was administered again alone in the evening as a $2 \mathrm{~mL}$ solution.

\section{Treatment Group 2}

- Days 1 to 21 (Period 1): morning administration of placebo via a standard jet nebulizer as a $3 \mathrm{~mL}$ solution, immediately followed by formoterol $20 \mu \mathrm{g}$ administered via a standard jet nebulizer as a $2 \mathrm{~mL}$ solution. Formoterol $20 \mu \mathrm{g}$ was administered again alone in the evening as a $2 \mathrm{~mL}$ solution.

- Days 22 to 42 (Period 2): morning administration of placebo mixed with formoterol $20 \mu \mathrm{g}$ via a standard jet nebulizer as a $5 \mathrm{~mL}$ solution. Formoterol $20 \mu \mathrm{g}$ was administered again alone in the evening as a $2 \mathrm{~mL}$ solution.
All patients received training on self-administration of revefenacin/placebo, and formoterol and patients were given albuterol as a rescue medication during the study. Study visits were conducted on Days 21 and 42 and laboratory tests, vital signs, and $\mathrm{FEV}_{1}$ and FVC pre- and post-dose were checked.

\section{Assessments and Endpoints}

The primary endpoint was the safety and tolerability of revefenacin when dosed sequentially with formoterol for 21 days, and the secondary endpoint was the safety and tolerability of combined dosing as a mixture of revefenacin and formoterol for 21 days. Safety was assessed according to the frequency and severity of treatment-emergent adverse events (AEs) and severe AEs, including COPD exacerbations, and treatment-emergent antimuscarinic AEs, use of rescue medication, physical examinations, vital sign measurements, clinical laboratory values, and ECG readings. The exploratory endpoint was to evaluate the change in lung function from baseline on Day 21 and Day 42. Spirometry was performed at 45 and 15 minutes pre-dose, and 1, 2, and 4 hours postdose using a flow-volume loop; methods used were those recommended by American Thoracic Society guidelines. ${ }^{9}$ A central spirometry vendor was used to provide standardized training, qualify the spirometry technician and oversee quality control of spirometry 
throughout the study.

\section{Statistical Analyses}

The safety population included all patients who were randomized into the study and received at least 1 dose of the study drug. AEs were coded to the preferred terms of the Medical Dictionary for Regulatory Activities, version 18.1. ${ }^{10}$ Summaries of the frequency and percentage of patients reporting each observed event were presented by using the preferred term, and severity and/or relatedness. Antimuscarinic treatment-emergent AEs were summarized using the following preferred terms: constipation, dry mouth, dysuria, worsening of urinary retention, worsening of narrow-angle glaucoma. ECG parameters (Fridericia'scorrected QT interval, PR interval, QT interval, QRS duration, respiration rate, and heart rate) were summarized in terms of observed values and change from baseline. Laboratory data (hematology and serum chemistry) were summarized in terms of observed values and changes from baseline. In addition, changes from baseline relative to normal ranges (i.e., shifts from normal to abnormal high/low) were summarized. The exploratory analysis was performed using the intention-to-treat population, which included all of the patients who were randomized into the study, received at least 1 dose of study drug and had at least 1 recorded post-baseline spirometry assessment. Trough FEV 1 was defined as the mean of the -45- and -15-minute pre-dose spirometry assessments and evaluated using an analysis of covariance model. Due to the descriptive nature of this study, the sample size was not based on formal hypothesis testing. Approximately 60 patients per group were randomized per treatment group ( $\mathrm{n}=120$ patients), providing approximately 51 patients per group and allowing for an approximate 15\% discontinuation rate post-randomization.

\section{Results}

\section{Patients}

Of the 122 patients randomized to the study, 63 and 59 patients were enrolled in the revefenacin and placebo groups, respectively, of whom 62 (98.4\%) and $55(93.2 \%)$ patients completed the treatment period and the study. Overall, there were 5 (4.1\%) patients who did not complete the study. The most frequently reported reasons for discontinuation were AEs (2 [1.6\%] patients) and withdrawal by the patient
(2 [1.6\%] patients). The former occurred exclusively in the placebo group, and the latter occurred in 1 patient from each treatment group (Figure 2). Demographic and baseline characteristics were similar between treatment groups (Table 1). Patients had a mean age of 64 years; $56.6 \%$ were men, and $95.1 \%$ were white (Table 1).

\section{Figure 2. Patient Disposition}

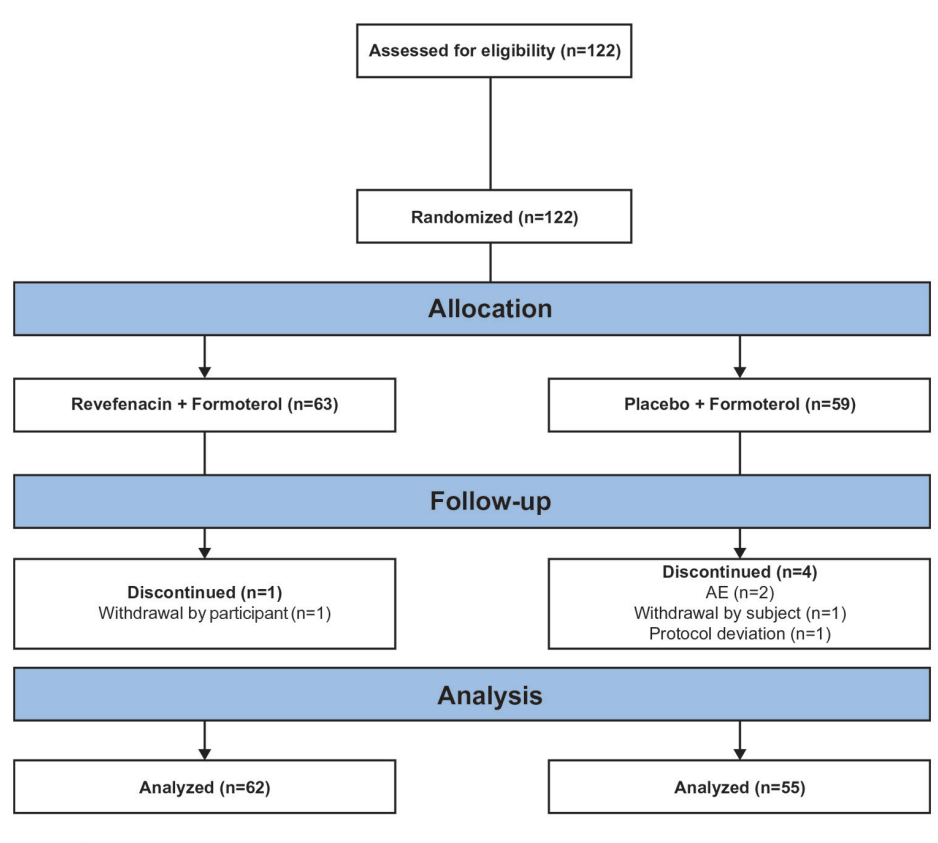

$\mathrm{AE}=$ adverse event

\section{Safety}

The incidence of AEs, regardless of treatment or timing of administration (sequential versus combination), did not exceed 7 patients and was higher in the placebo and formoterol group than in the revefenacin and formoterol group. Treatment-related AEs and moderate or severe drug-related AEs occurred exclusively in the placebo and formoterol group. AEs leading to study drug discontinuation occurred exclusively in the placebo and formoterol group during sequential administration. There were no fatal AEs, severe AEs, antimuscarinic AEs, or AEs leading to temporary interruption of the study drug. The most common AEs were worsening/exacerbation of COPD, cough, and dizziness (Table 2). Laboratory values over time were comparable between treatment groups, and changes from baseline to the end of the study were small and not clinically relevant. No clinically relevant changes in blood pressure or heart rate were observed over time. 


\section{Table 1. Patient Demographics and Baseline Characteristics: Intention-to-Treat Population}

\begin{tabular}{|c|c|c|}
\hline Characteristic & $\begin{array}{l}\text { REV } \\
(n=63)\end{array}$ & $\begin{array}{l}\text { PBO } \\
(n=59)\end{array}$ \\
\hline Age, y, mean (SD) & $63.1(8.7)$ & $64.4(8.4)$ \\
\hline Sex, male, n (\%) & $35(55.6)$ & 34 (57.6) \\
\hline Race, white, n (\%) & $60(95.2)$ & $56(94.9)$ \\
\hline BMI, $\mathrm{kg} / \mathrm{m}^{2}$, mean $(\mathrm{SD})$ & $29.22(6.6)$ & $29.11(6.3)$ \\
\hline Current Smoker, n (\%) & $37(58.7)$ & $32(54.2)$ \\
\hline Concurrent ICS Use, $\mathrm{n}(\%)$ & $13(20.6)$ & $15(25.4)$ \\
\hline COPD Duration, y, mean (SD) & $11.3(5.9)$ & $11.3(6.6)$ \\
\hline \multicolumn{3}{|l|}{ GOLD Airflow Category, n (\%) } \\
\hline 1 & 1 (1.6) & 0 \\
\hline 2 & $37(58.7)$ & $39(66.1)$ \\
\hline 3 & $23(36.5)$ & $19(32.2)$ \\
\hline 4 & $2(3.2)$ & $1(1.7)$ \\
\hline $\begin{array}{l}\text { Post-ipratropium Percent } \\
\text { Predicted FEV } 1, \% \text {, mean (SD) }\end{array}$ & $55.1(13.2)$ & $55.0(13.6)$ \\
\hline $\begin{array}{l}\text { Post-ipratropium } \text { FEV }_{\mathbf{1}} \text { to } \\
\text { FVC ratio, mean (SD) }\end{array}$ & $0.55(0.10)$ & $0.54(0.10)$ \\
\hline Baseline $\mathbf{F E V}_{\mathbf{1}}, \mathrm{L}$, mean (SD) & $1.34(0.48)$ & $1.34(0.50)$ \\
\hline \multicolumn{3}{|c|}{ Number of Exacerbations in the Past 12 Months, $n(\%)$} \\
\hline 0 & $52(82.5)$ & $46(78.0)$ \\
\hline 1 & $8(12.7)$ & 11 (18.6) \\
\hline$\geq 2$ & $3(4.8)$ & $2(3.4)$ \\
\hline
\end{tabular}

$\mathrm{REV}=$ revefenacin; $\mathrm{PBO}=$ placebo; $\mathrm{SD}=$ standard deviation; $\mathrm{BMI}=$ body mass index; ICS=inhaled corticosteroids; $\mathrm{COPD}=$ chronic obstructive pulmonary disease; $\mathrm{GOLD}=\mathrm{Global}$ Initiative for Chronic Obstructive Lung Disease; $\mathrm{FEV}_{1}=$ forced expiratory volume in 1 second; $\mathrm{FVC}=$ forced vital capacity

\section{Efficacy}

A greater change from baseline in trough $\mathrm{FEV}_{1}$ was observed in the revefenacin and formoterol group than in the placebo and formoterol group during sequential (least squares mean [95\% confidence interval (CI)] $157.09 \mathrm{~mL}$ [95.99, 218.19] versus $53.32 \mathrm{~mL}$ [-6.87, 113.51] respectively) and combination administration (least squares mean [95\% CI] $115.59 \mathrm{~mL}$ [55.17, $176.00]$ versus $34.98 \mathrm{~mL}[-25.63,95.59]$ respectively) (Figure 3). Results were similar for peak $\mathrm{FEV}_{1}$, trough FVC, and peak FVC (Table 3).

\section{Discussion}

The results of this 42-day, phase $3 \mathrm{~b}$ study demonstrated that the administration of revefenacin and formoterol via a standard jet nebulizer was well tolerated compared with placebo and formoterol, with numerically fewer
AEs associated with the revefenacin group. There were no differences in the incidence of AEs observed based on the timing of administration of study medications. AEs leading to study drug discontinuation occurred exclusively in the placebo group during sequential administration. However, given the low incidence (2 patients $[3.4 \%]$ ), this may not be clinically relevant since the order of sequential versus combination administration was not randomized within the study, and therefore, should not be interpreted as being attributable to sequential administration.

The safety profile of revefenacin in this study is consistent with published results evaluating the safety of patients taking revefenacin and comparable to previous studies of patients receiving LAMA/LABA combinations. Revefenacin $175 \mu \mathrm{g}$ was generally well tolerated in a 52-week trial in patients with moderate to very severe COPD and who received concomitant LABAs. ${ }^{3}$ A variety of LAMA/LABA (glycopyrronium/indacaterol, glycopyrrolate/ formoterol, tiotropium/olodaterol, and umeclidinium/ vilanterol) combinations were also shown to be well tolerated and have an acceptable safety profile in a range of studies. ${ }^{11-15}$

Although this study was not powered to show differences between treatments, the results demonstrated statistically significant improvements in lung function measured by change from baseline in trough $\mathrm{FEV}_{1}$ for revefenacin administered sequentially or in combination with formoterol compared with placebo during the 42 days. The trough $\mathrm{FEV}_{1}$ improvements with the revefenacin groups in this study are comparable with published results evaluating the efficacy of patients taking revefenacin, and previous studies evaluating the efficacy of patients receiving LAMA/LABA combinations. In a previous study, revefenacin treatment demonstrated clinically significant improvements in trough $\mathrm{FEV}_{1}$ and overall treatment effect trough FEV 1 versus placebo. ${ }^{4}$ A variety of LAMA/LABA (glycopyrronium/indacaterol, glycopyrrolate/formoterol, tiotropium/olodaterol, and umeclidinium/vilanterol) combinations also demonstrated clinically significant improvements in trough FEV $1 .{ }^{11-15}$

Several limitations should be noted for this trial. The treatment period was only 42 days, which does not allow for conclusions regarding long-term treatment. Due to the descriptive nature of this study, the sample size was not based on formal hypothesis testing. 


\section{Table 2. Summary of Adverse Events During Days 1-42: Safety Population}

\begin{tabular}{|c|c|c|c|c|}
\hline & $\begin{array}{c}\text { REV } \rightarrow \text { FOR } \\
\text { (Sequential) } \\
(n=63)\end{array}$ & $\begin{array}{c}\text { PBO } \rightarrow \text { FOR } \\
\text { (Sequential) } \\
(n=59)\end{array}$ & $\begin{array}{c}\text { REV + FOR } \\
\text { (Combination) } \\
(n=62)\end{array}$ & $\begin{array}{c}\mathrm{PBO}+\mathrm{FOR} \\
\text { (Combination) } \\
(\mathrm{n}=55)\end{array}$ \\
\hline $\mathbf{A E}, \mathrm{n}(\%)$ & $3(4.8)$ & $7(11.9)$ & $5(8.1)$ & $6(10.9)$ \\
\hline Moderate or Severe AE, n (\%) & 0 & $5(8.5)$ & $2(3.2)$ & $2(3.6)$ \\
\hline AE Related to Study Treatment, n (\%) & 0 & $2(3.4)$ & 0 & $2(3.6)$ \\
\hline $\begin{array}{l}\text { Moderate or Severe AE Related to Study } \\
\text { Treatment, } n(\%)\end{array}$ & 0 & $2(3.4)$ & 0 & $1(1.8)$ \\
\hline $\begin{array}{l}\text { AEs Leading to Permanent Study Treatment } \\
\text { Discontinuation, } \mathrm{n}(\%)\end{array}$ & 0 & $2(3.4)$ & 0 & 0 \\
\hline \multicolumn{5}{|l|}{ All AEs That Occurred During Study, n (\%) } \\
\hline COPD $^{a}$ & 0 & $2(3.4)$ & $1(1.6)$ & 0 \\
\hline Cough & 0 & 0 & 0 & $2(3.6)$ \\
\hline Dizziness & 0 & $2(3.4)$ & 0 & 0 \\
\hline Oropharyngeal Pain & $1(1.6)$ & 0 & 0 & $1(1.8)$ \\
\hline Abdominal Discomfort & 0 & 0 & 0 & $1(1.8)$ \\
\hline Arthralgia & 0 & 0 & 0 & $1(1.8)$ \\
\hline Headache & 0 & $1(1.7)$ & 0 & 0 \\
\hline Insomnia & $1(1.6)$ & 0 & 0 & 0 \\
\hline Increased Lacrimation & 0 & $1(1.7)$ & 0 & 0 \\
\hline Lipoma & 0 & $1(1.7)$ & 0 & 0 \\
\hline Muscle Contusion & 0 & 0 & $1(1.6)$ & 0 \\
\hline Oral Discomfort & $1(1.6)$ & 0 & 0 & 0 \\
\hline Pain in Extremity & 0 & 0 & $1(1.6)$ & 0 \\
\hline Peripheral Swelling & 0 & 0 & 0 & $1(1.8)$ \\
\hline Skin Lesion & 0 & 0 & $1(1.6)$ & 0 \\
\hline Sputum Purulent & 0 & 0 & $1(1.6)$ & 0 \\
\hline Tooth Infection & $1(1.6)$ & 0 & 0 & 0 \\
\hline Viral Infection & 0 & 0 & $1(1.6)$ & 0 \\
\hline Viral URTI & 0 & $1(1.7)$ & 0 & 0 \\
\hline
\end{tabular}

aworsening or exacerbation of COPD

$\mathrm{REV}=$ revefenacin; $\mathrm{FOR}=$ formoterol; $\mathrm{PBO}=$ placebo; $\mathrm{n}=$ number of participants treated; $\mathrm{AE}=\mathrm{adverse}$ event;

$\mathrm{COPD}=$ chronic obstructive pulmonary disease; URTI=upper respiratory-tract infection

Results should be interpreted with caution due to the small sample sizes. In addition, the efficacy endpoints were not powered to show differences between treatments. Furthermore, the order of sequential and combined administration was not randomized for each participant. Therefore, no inferences can be made about the relative effect of sequential and combined administration on trough $\mathrm{FEV}_{1}$. Larger studies that are powered to assess the long-term efficacy of revefenacin and formoterol via sequential or combination administration are needed.

In summary, there was no change in the safety profile when revefenacin was added to formoterol, whether administered sequentially before or combined via a standard jet nebulizer. There were significant improvements in trough $\mathrm{FEV}_{1}$ from baseline when revefenacin was given sequentially or combined with formoterol. Sequential or combined administration of a LAMA and LABA via a standard jet nebulizer could be a treatment option for patients with COPD, in particular, for those who require nebulized dual therapy. 
Figure 3. Least-squares Mean Change from Baseline in Trough Forced Expiratory Volume in 1 Second at Day 21 and Day 42: Intention-to-Treat Population
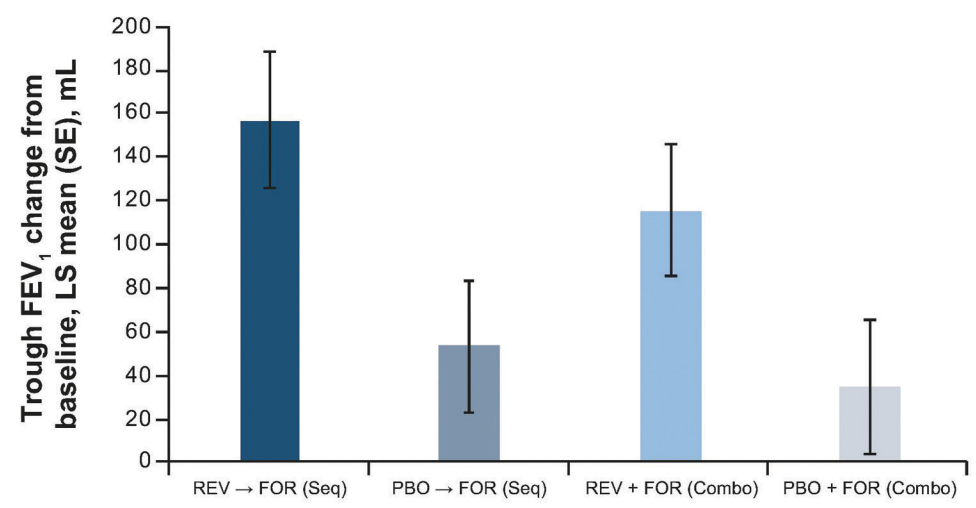

Number of evaluable patients ranged from $n=53$ to $n=59$.

$\mathrm{FEV}_{1}=$ forced expiratory volume in 1 second; $\mathrm{LS}=$ least squares; $\mathrm{SE}=$ standard error $\mathrm{REV}=$ revefenacin; $\mathrm{FOR}=$ formoterol; Seq=sequential; $\mathrm{PBO}=$ placebo; Combo=combination

\section{Acknowledgments}

The authors acknowledge Gráinne Faherty, MPharm, for medical writing and Frederique H. Evans, MBS, for editorial assistance in the preparation of the manuscript (Ashfield Healthcare Communications, Middletown, Connecticut).

\section{Declaration of Interest}

TMS received research support from West-Ward Pharmaceuticals, Theravance Biopharma US, Inc., GlaxoSmithKline, Pearl Therapeutics, Chiesi, AstraZeneca, Novartis, Boehringer Ingelheim, Forest, Compleware, Evidera, Novartis, Oncocyte, Teva, Vapotherm, Sunovion, Proterix BioPharma, Seer and Sanofi. He has also received speaker fees from GlaxoSmithKline, Mylan Inc./Theravance Biopharma US, Inc., and Sunovion, and consulting fees from Vapotherm. EJM and GDC are current employees of Theravance Biopharma US, Inc. CNB was an employee of Theravance Biopharma US, Inc., at the time this study was conducted.

\section{Table 3. Least-Squares Mean Change from Baseline in Trough and Peak Forced Vital Capacity Peak Forced Expiratory Volume in 1 Second at Day 21 and Day 42: Intention-to-Treat Population}

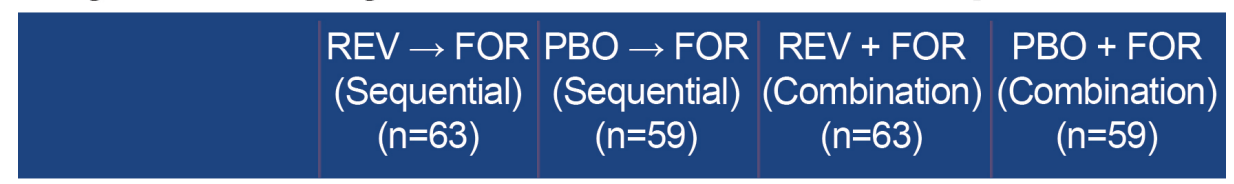

Trough FVC

\begin{tabular}{l|r|r|r|r}
\hline Evaluable, n & 57 & 54 & 59 & 53 \\
\hline LS Mean (SE), mL & $174.9(46.1)$ & $51.60(45.2)$ & $113.0(45.6)$ & $26.9(45.5)$ \\
\hline \multicolumn{1}{c|}{ Peak FVC } & & & & \\
\hline Evaluable, n & 58 & 54 & 58 & 53 \\
\hline LS Mean (SE), mL & $519.3(422.9)$ & $413.7(296.6)$ & $507.1(444.4)$ & $388.1(317.6)$ \\
\hline$\quad$ Peak FEV & & & & \\
\hline Evaluable, n & 58 & 54 & 58 & 53 \\
\hline LS Mean (SE), mL & $410.1(325.7)$ & $289.2(186.4)$ & $400.5(292.2)$ & $275.6(209.7)$ \\
\hline
\end{tabular}

Only includes records where both the observed and baseline results are available. Peak is defined as maximum value over 0 to 4 hours post-dose.

$\mathrm{REV}=$ revefenacin; $\mathrm{FOR}=$ formoterol; $\mathrm{PBO}=$ placebo; $\mathrm{FVC}=$ forced vital capacity; $\mathrm{FEV}_{1}=$ =forced expiratory volume in 1 second; $\mathrm{PBO}=$ placebo; $\mathrm{LS}=$ least squares; $\mathrm{SE}=$ standard error 


\section{References}

1. Global Initiative for Chronic Obstructive Lung Disease (GOLD). Global strategy for the diagnosis, management, and prevention of chronic obstructive pulmonary disease (2019 report). GOLD website. https://goldcopd.org/wp-content/uploads/2018/11/ GOLD-2019-POCKET-GUIDE-DRAFT-v1.7-14Nov2018-WMS. pdf. Published 2019. Accessed February 25, 2019.

2. Food and Drug Administration (FDA). Highlights of prescribing information Yupelri ${ }^{\oplus}$ (revefenacin) inhalation solution, for oral inhalation. FDA website. https:/www.accessdata.fda.gov/ drugsatfda_docs/label/2018/210598s000lbl.pdf.

Published November 2018. Accessed February 25, 2019.

3. Donohue J, Kerwin E, Sethi S, et al. Revefenacin, a once-daily, lung-selective, long-acting muscarinic antagonist for nebulized therapy: safety and tolerability results of a 52-week phase 3 trial in moderate to very severe chronic obstructive pulmonary disease. Respir Med. 2019;153:38-43.

doi: https://doi.org/10.1016/j.rmed.2019.05.010

4. Ferguson G, Feldman G, Pudi K, et al. Improvements in lung function with nebulized revefenacin in the treatment of patients with moderate to very severe COPD: results from two replicate phase III clinical trials. Chronic Obstr Pulm Dis. 2019;6(2):154165. doi: https://doi.org/10.15326/jcopdf.6.2.2018.0152

5. Donohue J, Kerwin E, Sethi S, et al. Maintained therapeutic effect of revefenacin over 52 weeks in moderate to very severe chronic obstructive pulmonary disease (COPD). Respir Res. 2019;20(1):241. doi: https://doi.org/10.1186/s12931-019-1187-7

6. Barrons R, Wheeler J, Woods J. Opportunities for inhaler device selection in elderly patients with asthma or COPD. Patient Intell. 2015;7:53-65. doi: https://doi.org/10.2147/PI.S61200

7. International Conference on Harmonisation (ICH). Integrated addendum to ICH harmonised guideline: guideline for good clinical practice E6 (R2). https://www.fda.gov/regulatoryinformation/search-fda-guidance-documents/e6r2-goodclinical-practice-integrated-addendum-ich-e6r 1.

Published 2015. Accessed April 20, 2019.

8. World Medical Association. World Medical Association Declaration of Helsinki: ethical principles for medical research involving human subjects. JAMA. 2013;310(20):2191-2194. doi: https://doi.org/10.1001/jama.2013.281053

9. Miller M, Hankinson J, Brusasco V, et al. Standardisation of spirometry. Eur Respir J. 2005;26(2):319-338.

doi: https://doi.org/10.1183/09031936.05.00034805

10. Medical Dictionary for Regulatory Activities. (MeDRA). International Conference on Harmonisation (ICH). ICH harmonisation for better health. Introductory guide MedDRA version 18.1. MeDRA website. https://www.meddra.org/ sites/default/files/guidance/file/intguide_18_1_english.pdf. Published September 2015. Accessed May 14, 2019.
11. Bateman E, Ferguson G, Barnes N, et al. Dual bronchodilation with QVA149 versus single bronchodilator therapy: the SHINE study. Eur Respir J. 2013;42(6):1484-1494.

doi: https://doi.org/10.1183/09031936.00200212

12. Buhl R, Maltais F, Abrahams R, et al. Tiotropium and olodaterol fixed-dose combination versus mono-components in COPD (GOLD 2-4). Eur Respir J. 2015;45(4):969-979. doi: https://doi.org/10.1183/09031936.00136014

13. Dahl R, Chapman K, Rudolf M, et al. Safety and efficacy of dual bronchodilation with QVA149 in COPD patients: the ENLIGHTEN study. Respir Med. 2013;107(10):1558-1567. doi: https://doi.org/10.1016/j.rmed.2013.05.016

14. Donohue J, Maleki-Yazdi M, Kilbride S, Mehta R, Kalberg C, Church A. Efficacy and safety of once-daily umeclidinium/ vilanterol 62.5/25 mcg in COPD. Respir Med. 2013;107(10):15381546. doi: https://doi.org/10.1016/j.rmed.2013.06.001

15. Martinez F, Rabe K, Ferguson G, et al. Efficacy and safety of glycopyrrolate/formoterol metered dose inhaler formulated using co-suspension delivery technology in patients with COPD. Chest. 2017;151(2):340-357.

doi: https://doi.org/10.1016/j.chest.2016.11.028 